Buletin Ilmiah Math. Stat. Dan Terapannya (Bimaster)

Volume 08, No. 3 (2019), hal 619-626.

\title{
RADIUS, DIAMETER DAN CENTER DARI GRAF FUZZY BERARAH
}

\author{
Ayu Fitriani, Mariatul Kiftiah, Fransiskus Fran
}

\section{INTISARI}

\begin{abstract}
Sebuah graf fuzzy $G=(V, \mu, \rho)$ adalah himpunan tak kosong $V$ dengan sepasang fungsi dari $\mu: V \rightarrow[0,1]$ dan $\rho: V \times V \rightarrow[0,1]$ sedemikian sehingga untuk setiap $x, y$ di $V, \rho(x, y) \leq$ $\min \{\mu(x), \mu(y)\}$. Penelitian ini menggunakan kasus khusus dimana $\mu(x)=1$, untuk setiap $x \in V$ dan $\rho(x, y) \in[0,1], \forall x, y \in V \times V$. Penelitian ini menentukan nilai radius, diameter dan center pada graf fuzzy berarah dan mengkaji pengaruh arah pada graf terhadap hasil dari radius, diameter dan center. Pada graf fuzzy roda berarah $W_{4}$ terbentuk 14 graf berdasarkan arah keluar dari simpul pusat $v_{0}$, dimana untuk 1 arah keluar terbentuk 4 graf, untuk 2 arah keluar terbentuk 6 graf dan untuk 3 arah keluar terbentuk 4 graf. Radius, diameter dan center dari graf fuzzy roda berarah diperoleh dengan menggunakan teori eksentrisitas. Radius, diameter yang diperoleh adalah berupa nilai dengan interval tertutup [0,1]. Center berupa graf trivial, graf kosong dan graf terhubung dan arah mempengaruhi radius, diameter dan center pada graf fuzzy roda berarah $W_{4}$, hasil radius, diameter dan center ada yang berbeda untuk 1 arah keluar, 2 arah keluar dan 3 arah keluar dari simpul pusat $v_{0}$ dari graf roda.
\end{abstract}

Kata kunci : graf roda, eksentrisitas, graffuzzy

\section{PENDAHULUAN}

Teori graf pertama kali diperkenalkan oleh ahli matematika asal Swiss, Leonard Euler pada tahun 1736 [1]. Beberapa jenis graf memiliki ciri-ciri khusus, diantaranya graf lingkaran $\left(C_{n}\right)$ dan graf roda $\left(W_{n}\right)$. Graf lingkaran merupakan graf sederhana yang setiap simpulnya berderajat dua. Graf roda merupakan graf yang diperoleh dengan cara menambahkan satu simpul pada graf lingkaran $C_{n}$, dan menghubungkan simpul baru tersebut dengan semua simpul pada graf lingkaran tersebut [2].

Salah satu pembahasan yang terus berkembang pada teori graf adalah eksentrisitas titik dari suatu graf. Secara umum, eksentrisitas pada suatu graf $G=(V, E)$ diartikan sebagai jarak maksimal dari $u, v \in V$ pada graf $G$. Radius dari $G$ yang dinotasikan $\operatorname{rad}(G)$ adalah eksentrisitas minimum dari setiap titik $G$, sedangkan diameter dari $G$ yang dinotasikan $\operatorname{diam}(G)$ adalah eksentrisitas maksimum dari setiap titik di $G$. Titik $u$ disebut titik sentral jika $e(u)=\operatorname{rad}(G)$ [3].

Pada perkembangannya, teori eksentrisitas pada suatu graf juga dapat diterapkan pada graf fuzzy yang diperkenalkan oleh Azriel Rosenfeld pada tahun 1975 yang merupakan kombinasi dari teori graf dan himpunan fuzzy. Dalam penerapannya, graf fuzzy diterapkan dalam banyak teori seperti cluster analysis [4] dan Database Theory [5]. Himpunan fuzzy merupakan pengembangan dari himpunan tegas (crisp set). Jika pada himpunan tegas keanggotaannya ditentukan secara tegas apakah termasuk anggota dan bukan anggota, namun pada himpunan fuzzy memiliki derajat keanggotaan yang nilainya berada dalam interval tertutup [0,1] [1]. Suatu graf fuzzy yang dinotasikan dengan $G=(V, \mu, \rho)$ atau disingkat $G=(\mu, \rho)$, fungsi $\mu$ memetakan himpunan simpul ke interval tertutup $[0,1]$ dan fungsi 
$\rho$ memetakan himpunan sisi ke interval tertutup $[0,1]$ yang memenuhi $\rho(u, v) \leq \min \{\mu(u), \mu(v)\}$ [6],[7].

Penelitian ini menentukan nilai radius, diameter dan center pada graf fuzzy roda berarah dan mengkaji pengaruh arah pada graf terhadap hasil dari radius, diameter dan center. Pada penelitian ini graf yang digunakan adalah graf fuzzy terhubung kuat, dan arah pada sisi luar graf searah dengan jarum jam.

Untuk menentukan radius, diameter dan center pada graf fuzzy dilakukan dengan tiga langkah, yaitu langkah pertama adalah menentukan jarak fuzzy dari setiap simpul ke setiap simpul yang lain dalam graf $G$ yang merupakan nilai minimum dari perkalian antara panjang sisi dan bobot terkecil dari simpul $u$ ke simpul $v$. Setelah jarak fuzzy diketahui selanjutnya langkah kedua adalah menentukan eksentrisitas dari setiap simpul dalam graf $G$ yang merupakan nilai maksimum dari jarak fuzzy. Langkah ketiga adalah menentukan radius, diameter dan center dengan mencari radius yang merupakan nilai minimum dari eksentrisitas fuzzy, diameter yang merupakan nilai maksimum dari eksentrisitas fuzzy, titik sentral yang merupakan titik yang nilai nya sama dengan radius, dan center yang diperoleh dengan membentuk titik-titik sentral menjadi subgraf [8].

\section{GRAF FUZZY}

Graf adalah pasangan $(V, E)$ dengan elemen dari $V$ sebagai simpul dari graf dan elemen dari $E$ adalah sebagai sisi. Dengan demikian, setiap relasi fuzzy $\rho$ pada sebuah subset fuzzy $\mu$ dari himpunan $V$ dapat didefinisikan sebagai graf $f u z z y$, dimana sisi $(u, v) \in V \times V$ memiliki bobot $\rho(u, v) \in[0,1]$. Secara formal, sebuah graf fuzzy $G=(V, \mu, \rho)$ adalah himpunan simpul tak kosong $V$ dengan sebuah pasangan dari fungsi $\mu: V \rightarrow[0,1]$ dan $\rho: V \times V \rightarrow[0,1]$ sedemikian sehingga untuk setiap $u, v$ di $V$, $\rho(u, v) \leq \min \{\mu(u), \mu(v)\}$. Fungsi $\rho$ adalah sebuah relasi fuzzy di $\mu$. Dengan demikian dalam kasus yang paling umum, simpul dan sisi memiliki derajat keanggotaan, dalam interval $[0,1]$ pada kasus khusus dengan $\mu(u)=1$, untuk semua $u \in V$. Demikian pula, graf fuzzy $H=(P, v, \tau)$ disebut sebuah subgraf fuzzy dari $G=(V, \mu, \rho)$, jika $P \subseteq V, v(u)=\mu(u)$ untuk semua $u \in P$ dan $\tau(u, v)=\rho(u, v)$ untuk semua $u, v \in P$ [5]. Sebagai ilustrasi, diberikan sebuah graf fuzzy $G$ sebagai berikut:

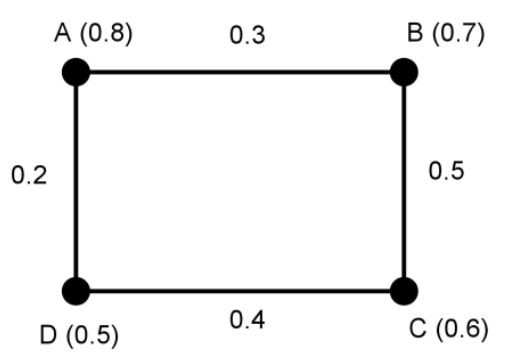

Gambar 1 Graf fuzzy G

Berdasarkan Gambar 1 graf fuzzy $G$ memiliki empat simpul dan empat sisi, setiap simpul dan sisi memiliki derajat keanggotaan dengan interval $[0,1]$. Pada simpul A memiliki derajat keanggotaan 0.8 dapat ditulis $\mu(A)=0.8$, simpul B dapat ditulis $\mu(B)=0.7$, simpul $\mathrm{C}$ dapat ditulis $\mu(C)=0.6$, simpul D dapat ditulis $\mu(D)=0.5$ dengan $\mu(S)$ dimana $A, B, C, D \in S$ adalah himpunan titik fuzzy. Pada sisi $(A, B)$ memiliki derajat keanggotaan 0.3 dapat ditulis $\rho(A, B)=0.3, \rho(B, C)=0.5$, $\rho(C, D)=0.4, \rho(A, D)=0.2$, dimana $(A, B),(B, C),(C, D),(A, D) \in S \times S$ adalah himpunan sisi fuzzy.

Pada kasus graf fuzzy yang memiliki arah, didefinisikan sebuah graf fuzzy berarah (fuzzy digraf) dinotasikan dengan $D=(V, \mu, \delta)$, dimana $\mu$ adalah sebuah subset fuzzy dari $V$ dan $\delta$ adalah sebuah subset fuzzy dari $V \times V$ sedemikian sehingga $\delta(u, v) \leq \min \{\mu(u), \mu(v)\}$. Sebagai ilustrasi diberikan pada Gambar 2 berikut. 


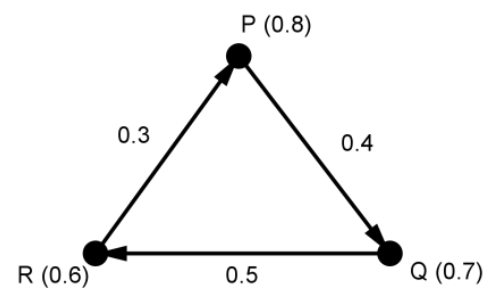

Gambar 2 Graf fuzzy berarah

Berdasarkan Gambar 2 graf fuzzy G memiliki tiga simpul dan tiga sisi, setiap simpul dan sisi memiliki nilai keanggotaan dengan interval $[0,1]$. Pada simpul $\mathrm{P}$ memiliki derajat keanggotaan 0.8 dapat ditulis $\mu(P)=0.8$, simpul Q dapat ditulis $\mu(Q)=0.7$, simpul $\mathrm{R}$ dapat ditulis $\mu(R)=0.6$. Pada sisi $(P, Q)$ memiliki derajat keanggotaan 0.4 dan sisi berarah dari simpul $\mathrm{P}$ menuju $\mathrm{Q}$ dapat ditulis $\delta(P, Q)=0.4$, simpul $\mathrm{Q}$ menuju $\mathrm{R}$ dapat ditulis $\delta(Q, R)=0.5$, simpul $\mathrm{R}$ menuju $\mathrm{P}$ dapat ditulis $\delta(R, P)=0.3$.

\section{EKSENTRISITAS TITIK GRAF}

Eksentrisitas titik graf yang dinotasikan $e(v)$ dari $v$ di graf $G$ adalah jarak terjauh (maksimal lintasan terpendek) dari $u$ ke setiap $v$ di $G$, atau dapat ditulis $e(v)=\operatorname{maks}\{d(v, u) \mid \forall u \in G\}$. Titik $v$ disebut titik eksentrik jika jarak dari $v$ ke $u$ sama dengan $e(u)$. Radius dari $G$ yang dinotasikan $\operatorname{rad}(G)$ adalah eksentrisitas minimum dari setiap titik $G$, dapat ditulis $\operatorname{rad}(G)=\min \{e(v) \mid \forall v \in G\}$ sedangkan diameter dari $G$ yang dinotasikan $\operatorname{diam}(G)$ adalah eksentrisitas maksimum dari setiap titik di $G$ dapat ditulis $\operatorname{diam}(G)=\operatorname{maks}\{e(v) \mid \forall v \in G\}$. Titik $v$ disebut titik sentral jika $e(v)=\operatorname{rad}(G)$. Pusat graf (Center) yang dinotasikan $\operatorname{Cen}(G)$ dari graf terhubung $G$ adalah subgraf yang diinduksi oleh titik sentral. Eksentrisitas dari sebuah titik $v$ dari $D$ didefinisikan sebagai $e(v)=\operatorname{maks}_{w \in V(D)} d(v, w)$. Radius dari $D$ yang dinotasikan $\operatorname{rad}(D)=\min _{w \in V(D)} e(v)$ dan center yang dinotasikan $\operatorname{Cen}(D)$ didefinisikan sebagai subgraf yang diinduksi dari titik-titik sentral.

Teori Eksentrisitas titik pada graf biasa juga dapat digunakan pada graf fuzzy yang disebut eksentrisitas fuzzy yang dinotasikan dengan $e_{f}(v)$. Oleh karena itu, penentuan radius, diameter dan center juga menggunakan teori eksentrisitas pada graf biasa. Cara mencari jarak pada graf biasa berbeda dengan cara mencari jarak pada graf fuzzy.

\section{RADIUS, DIAMETER DAN CENTER DARI GRAF FUZZY BERARAH}

Pada perkembangannya, konsep teori eksentrisitas pada graf biasa dapat digunakan pada graf fuzzy. Dalam menentukan eksentrisitas terlebih dahulu akan dicari jarak dari setiap simpul, konsep jarak pada graf biasa berbeda pada graf fuzzy, karena pada graf fuzzy terdapat nilai pada setiap sisi graf. Diperlukan tiga langkah dalam menentukan radius, diameter dan center dari sebuah graf fuzzy berarah dengan langkah-langkah sebagai berikut [8] :

1. Mencari jarak fuzzy $d_{f}(u, v)$, yang didefinisikan $d_{f}(u, v)=\min \{l(P) * S(P)\}$ dimana $P$ adalah sebuah lintasan dari $u-v, l(P)$ adalah panjang lintasan dan $S(P)$ adalah bobot fuzzy minimum pada lintasan di $P$, dimana $*$ mempresentasikan perkalian biasa.

2. Mencari eksentrisitas dari semua simpul dalam graf fuzzy tersebut $e_{f}(u)$.

3. Menentukan radius dari eksentrisitas dengan memperhatikan nilai minimum dari eksentrisitas yang dinotasikan $r_{f}(G)=\min _{u \in V}\left\{e_{f}(u)\right\}$. Menentukan diameter dari eksentrisitas dengan memperhatikan nilai maksimum dari eksentrisitas yang dinotasikan $d_{f}(G)=\operatorname{maks}_{u \in V}\left\{e_{f}(u)\right\}$. Titik sentral diperoleh dari titik yang memiliki nilai eksentrisitas fuzzy yang minimum. 
Menentukan center dari eksentrisitas dengan memperhatikan titik eksentrisitas, yaitu subgraf yang diinduksi oleh himpunan semua titik sentral fuzzy disebut center graf fuzzy.

Pada graf fuzzy roda berarah $W_{4}$ terbentuk 14 graf berdasarkan arah keluar dari simpul $v_{0}$, yaitu pada 1 arah keluar terbentuk 4 graf dapat dilihat pada Gambar 3, 2 arah keluar terbentuk 6 graf dapat dilihat pada Gambar 5 dan 3 arah keluar terbentuk 4 graf dapat dilihat pada Gambar 7. Untuk selanjutnya dari tiap graf yang dihasilkan akan dihitung radius dan diameter.

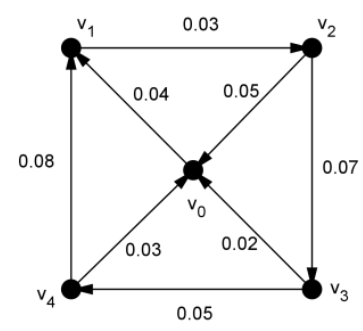

(a)

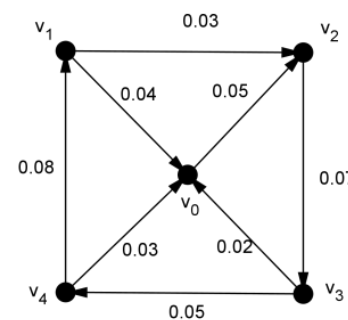

(b)

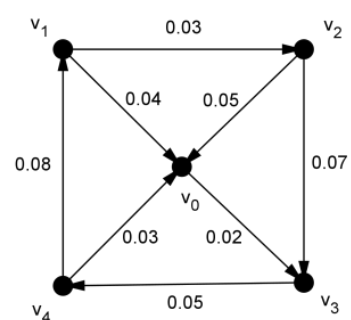

(c)

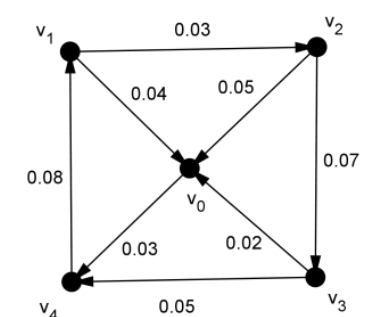

(d)

Gambar 3 Empat bentuk graf fuzzy roda berarah $W_{4}$ dari satu arah keluar

Berikut akan dibahas salah satu graf fuzzy roda berarah $W_{4}$ pada Gambar 3, yaitu 3 (d) terlebih dahulu. Akan ditentukan radius, diameter dan center dengan langkah-langkah sebagai berikut.

Penyelesaian :

1. Mencari jarak fuzzy dari semua simpul

i. $\quad d_{f}\left(v_{0}, v_{1}\right)=\min \{2 \times 0.03\}=0.06$

$d_{f}\left(v_{0}, v_{2}\right)=\min \{3 \times 0.03\}=0.09$

$d_{f}\left(v_{0}, v_{3}\right)=\min \{4 \times 0.03\}=0.12$

$d_{f}\left(v_{0}, v_{4}\right)=\min \{1 \times 0.03\}=0.03$

ii. $\quad d_{f}\left(v_{1}, v_{0}\right)=\min \{1 \times 0.04,2 \times 0.03,3 \times 0.02\}=0.04$

$d_{f}\left(v_{1}, v_{2}\right)=\min \{1 \times 0.03\}=0.03$

$d_{f}\left(v_{1}, v_{3}\right)=\min \{2 \times 0.03\}=0.06$

$d_{f}\left(v_{1}, v_{4}\right)=\min \{2 \times 0.03,3 \times 0.03,3 \times 0.03,4 \times 0.02\}=0.06$

iii. $\quad d_{f}\left(v_{2}, v_{0}\right)=\min \{1 \times 0.05,2 \times 0.02,4 \times 0.04\}=0.04$

$d_{f}\left(v_{2}, v_{1}\right)=\min \{3 \times 0.03,3 \times 0.05,4 \times 0.02\}=0.08$

$d_{f}\left(v_{2}, v_{3}\right)=\min \{1 \times 0.07\}=0.07$

$d_{f}\left(v_{2}, v_{4}\right)=\min \{2 \times 0.05,2 \times 0.03,3 \times 0.02\}=0.06$

iv. $\quad d_{f}\left(v_{3}, v_{0}\right)=\min \{1 \times 0.02,3 \times 0.04,4 \times 0.03\}=0.02$

$d_{f}\left(v_{3}, v_{1}\right)=\min \{2 \times 0.05,3 \times 0.02\}=0.06$

$d_{f}\left(v_{3}, v_{2}\right)=\min \{3 \times 0.03,4 \times 0.02\}=0.08$

$d_{f}\left(v_{3}, v_{4}\right)=\min \{1 \times 0.05,2 \times 0.02\}=0.04$

v. $\quad d_{f}\left(v_{4}, v_{0}\right)=\min \{2 \times 0.04,3 \times 0.03\}=0.08$

$d_{f}\left(v_{4}, v_{1}\right)=\min \{1 \times 0.08\}=0.08$

$d_{f}\left(v_{4}, v_{2}\right)=\min \{2 \times 0.03\}=0.06$

$d_{f}\left(v_{4}, v_{3}\right)=\min \{3 \times 0.03\}=0.09$

2. Mencari eksentrisitas dari semua simpul

$$
\begin{aligned}
e_{f}\left(v_{0}\right) & =\operatorname{maks}\left\{d_{f}\left(v_{0}, v_{1}\right), d_{f}\left(v_{0}, v_{2}\right), d_{f}\left(v_{0}, v_{3}\right), d_{f}\left(v_{0}, v_{4}\right)\right\} \\
& =\operatorname{maks}\{0.06,0.09,0.12,0.03\} \\
& =0.12
\end{aligned}
$$




$$
\begin{aligned}
e_{f}\left(v_{1}\right) & =\operatorname{maks}\left\{d_{f}\left(v_{1}, v_{0}\right), d_{f}\left(v_{1}, v_{2}\right), d_{f}\left(v_{1}, v_{3}\right), d_{f}\left(v_{1}, v_{4}\right)\right\} \\
& =\operatorname{maks}\{0.04,0.03,0.06,0.06\} \\
& =0.06 \\
e_{f}\left(v_{2}\right) & =\operatorname{maks}\left\{d_{f}\left(v_{2}, v_{0}\right), d_{f}\left(v_{2}, v_{1}\right), d_{f}\left(v_{2}, v_{3}\right), d_{f}\left(v_{2}, v_{4}\right)\right\} \\
& =\operatorname{maks}\{0.04,0.08,0.07,0.06\} \\
& =0.08 \\
e_{f}\left(v_{3}\right) & =\operatorname{maks}\left\{d_{f}\left(v_{3}, v_{0}\right), d_{f}\left(v_{3}, v_{1}\right), d_{f}\left(v_{3}, v_{2}\right), d_{f}\left(v_{3}, v_{4}\right)\right\} \\
& =\operatorname{maks}\{0.02,0.06,0.08,0.04\} \\
& =0.08 \\
e_{f}\left(v_{4}\right) & =\operatorname{maks}\left\{d_{f}\left(v_{4}, v_{0}\right), d_{f}\left(v_{4}, v_{1}\right), d_{f}\left(v_{4}, v_{2}\right), d_{f}\left(v_{4}, v_{3}\right)\right\} \\
& =\operatorname{maks}\{0.08,0.08,0.06,0.09\} \\
& =0.09
\end{aligned}
$$

3. Menentukan radius, diameter dan center

$$
\begin{aligned}
r_{f}(G)=\min _{u \in V} & \left\{e_{f}(u)\right\} \\
= & \min \left\{e_{f}\left(v_{0}\right), e_{f}\left(v_{1}\right), e_{f}\left(v_{2}\right), e_{f}\left(v_{3}\right), e_{f}\left(v_{4}\right)\right\} \\
= & \min \{0.12,0.06,0.08,0.08,0.09\} \\
= & 0.06 \\
d_{f}(G)=\operatorname{maks}_{u \in V} & \left\{e_{f}(u)\right\} \\
& =\operatorname{maks}\left\{e_{f}\left(v_{0}\right), e_{f}\left(v_{1}\right), e_{f}\left(v_{2}\right), e_{f}\left(v_{3}\right), e_{f}\left(v_{4}\right)\right\} \\
& =\operatorname{maks}\{0.12,0.06,0.08,0.08,0.09\} \\
& =0.12
\end{aligned}
$$

Karena $r_{f}(G)=e_{f}\left(v_{1}\right)=0.06$ maka titik $v_{1}$ merupakan titik sentral. Sehingga center yang diperoleh berupa graf trivial yang hanya memiliki satu simpul saja yaitu simpul $v_{1}$.

Berdasarkan pada penghitungan untuk graf pada Gambar 3 (d). Dengan cara yang sama diperoleh radius, diameter dan center dari semua graf pada satu arah keluar, yang ditunjukkan pada Tabel 1 berikut :

Tabel 1 Hasil radius, diameter dan titik sentral graf fuzzy roda berarah $W_{4}$ dari satu arah keluar

\begin{tabular}{|c|c|c|c|}
\hline Satu arah keluar & Radius & Diameter & Titik sentral \\
\hline$v_{0} \operatorname{ke} v_{1}$ & 0.06 & 0.12 & $v_{3}$ \\
\hline$v_{0} \operatorname{ke} v_{2}$ & 0.09 & 0.20 & $v_{1}$ dan $v_{4}$ \\
\hline$v_{0} \operatorname{ke} v_{3}$ & 0.06 & 0.10 & $v_{1}$ \\
\hline$v_{0} \operatorname{ke} v_{4}$ & 0.06 & 0.12 & $v_{1}$ \\
\hline
\end{tabular}

Berdasarkan Tabel 1 pada arah $v_{0}$ ke $v_{2}$ diperoleh center berupa graf terhubung dan pada arah $v_{0}$ ke $v_{1}, v_{0}$ ke $v_{3}$ dan $v_{0}$ ke $v_{4}$ adalah graf trivial, yang diilustrasikan pada Gambar 5 berikut. 
(a) Center dari $v_{0} k e v_{1}$

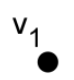

(c) Center dari $\mathrm{v}_{0}$ ke $\mathrm{v}_{3}$

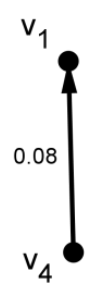

(b) Center dari $\mathrm{v}_{0} \mathrm{ke} \mathrm{v}_{2}$

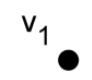

(d) Center dari $\mathrm{v}_{0}$ ke $\mathrm{v}_{4}$

Gambar 4 Empat center graf fuzzy roda berarah $W_{4}$ dari satu arah keluar

Untuk dua arah keluar dari simpul pusat $v_{0}$ pada graf fuzzy roda berarah $W_{4}$ terbentuk empat graf, yang diilustrasikan pada Gambar 5 berikut.

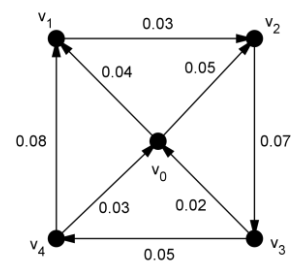

(a)

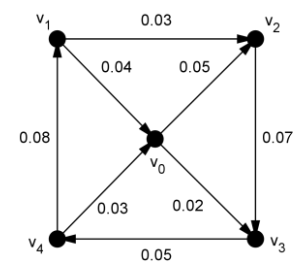

(d)

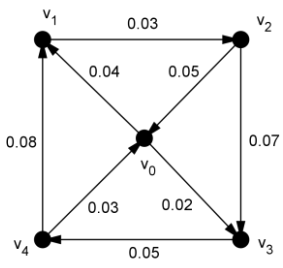

(b)

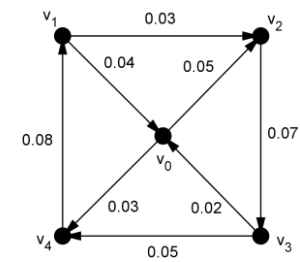

(e)

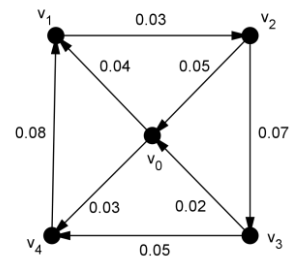

(c)

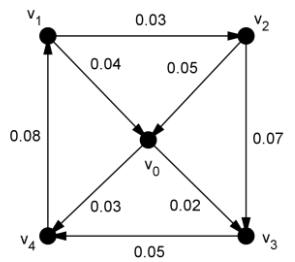

(f)

Gambar 5 Enam bentuk graf fuzzy roda berarah $W_{4}$ dari dua arah keluar

Dapat dilihat pada Gambar 5(a), graf tersebut adalah graf fuzzy roda berarah $W_{4}$ dengan arah keluar dari simpul $v_{0}$ ke $v_{1}$ dan $v_{2}$, Gambar 5(b) adalah graf fuzzy roda berarah $W_{4}$ dengan arah keluar dari simpul $v_{0}$ ke $v_{1}$ dan $v_{3}$, Gambar 6(c) adalah graf fuzzy roda berarah $W_{4}$ dengan arah keluar dari simpul $v_{0}$ ke $v_{1}$ dan $v_{4}$, Gambar 6(d) adalah graf fuzzy roda berarah $W_{4}$ dengan arah keluar dari simpul $v_{0}$ ke $v_{2}$ dan $v_{3}$, Gambar 5(e) adalah graf fuzzy roda berarah $W_{4}$ dengan arah keluar dari simpul $v_{0}$ ke $v_{2}$ dan $v_{4}$, Gambar 5(f) adalah graf fuzzy roda berarah $W_{4}$ dengan arah keluar dari simpul $v_{0}$ ke $v_{3}$ dan $v_{4}$.

Selanjutnya akan ditentukan radius, diameter dan center dari graf pada Gambar 5. Menggunakan cara yang sama diperoleh radius, diameter dan center dari semua graf pada dua arah keluar, yang ditunjukkan pada Tabel 2 berikut :

Tabel 2 Hasil radius, diameter dan titik sentral graf fuzzy roda berarah $W_{4}$ dari dua arah keluar

\begin{tabular}{|c|c|c|c|}
\hline Dua arah keluar & Radius & Diameter & Titik sentral \\
\hline$v_{0}$ ke $v_{1}$ dan $v_{2}$ & 0.05 & 0.12 & $v_{3}$ \\
\hline$v_{0}$ ke $v_{1}$ dan $v_{3}$ & 0.06 & 0.09 & $v_{0}$ \\
\hline$v_{0}$ ke $v_{1}$ dan $v_{4}$ & 0.06 & 0.09 & $v_{3}$ \\
\hline$v_{0}$ ke $v_{2}$ dan $v_{3}$ & 0.06 & 0.15 & $v_{0}$ dan $v_{1}$ \\
\hline$v_{0}$ ke $v_{2}$ dan $v_{4}$ & 0.06 & 0.10 & $v_{1}$ dan $v_{3}$ \\
\hline$v_{0}$ ke $v_{3}$ dan $v_{4}$ & 0.06 & 0.12 & $v_{1}$ \\
\hline
\end{tabular}


Berdasarkan Tabel 2 pada arah $v_{0}$ ke $v_{1}$ dan $v_{2}, v_{0}$ ke $v_{1}$ dan $v_{3}, v_{0}$ ke $v_{1}$ dan $v_{4}, v_{0}$ ke $v_{3}$ dan $v_{4}$ memliki center berupa graf trivial, pada arah $v_{0}$ ke $v_{2}$ dan $v_{3}$ berupa graf kosong dan pada arah $v_{0}$ ke $v_{2}$ dan $v_{4}$ diperoleh center berupa graf terhubung, yang diilustrasikan pada Gambar 6 berikut.

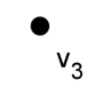

(a) Center dari $v_{0}$ ke $v_{1}$ dan $v_{2}$

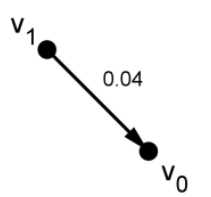

(d) Center dari $v_{0}$ ke $v_{2}$ dan $v_{3}$

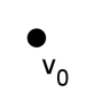

(b) Center dari $v_{0}$ ke $v_{1}$ dan $v_{3}$

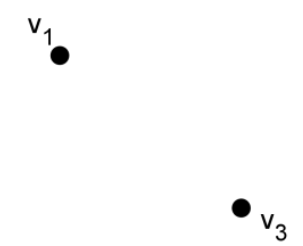

(e) Center dari $v_{0}$ ke $v_{2}$ dan $v_{4}$ (c) Center dari $v_{0} k e v_{1}$ dan $v_{4}$

(f) Center dari $v_{0}$ ke $v_{3}$ dan $v_{4}$

Gambar 6 Enam center graf fuzzy roda berarah $W_{4}$ dari dua arah keluar

Untuk tiga arah keluar dari simpul pusat $v_{0}$ pada graf fuzzy roda berarah $W_{4}$ terbentuk empat graf, yang diilustrasikan pada Gambar 7 berikut.

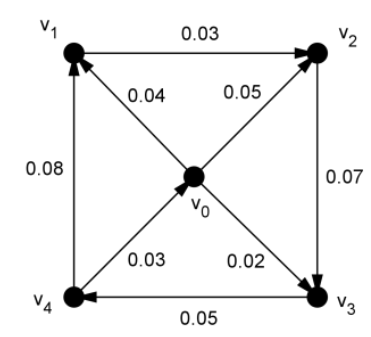

(a)

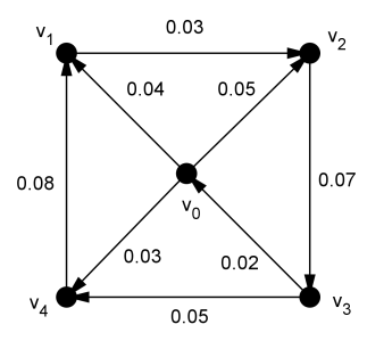

(b)

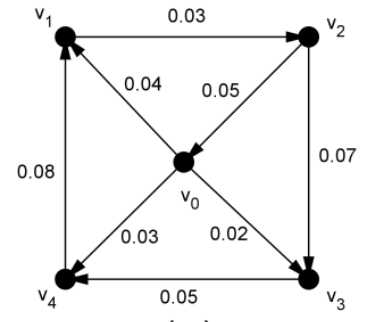

(c)

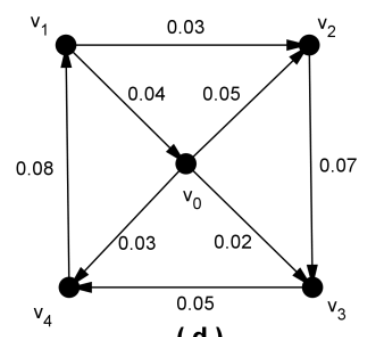

(d)

Gambar 7 Empat bentuk graf fuzzy roda berarah $W_{4}$ dari tiga arah keluar

Dapat dilihat Gambar 7(a) adalah graf fuzzy roda berarah $W_{4}$ dengan arah keluar dari simpul $v_{0}$ ke $v_{1}, v_{2}$, dan $v_{3}$, Gambar 7(b) adalah graf fuzzy roda berarah $W_{4}$ dengan arah keluar dari simpul $v_{0}$ ke $v_{1}, v_{2}$ dan $v_{4}$, Gambar 7(c) adalah graf fuzzy roda berarah $W_{4}$ dengan arah keluar dari simpul $v_{0}$ ke $v_{1}, v_{3}$ dan $v_{4}$, Gambar $7(\mathrm{~d})$ adalah graf fuzzy roda berarah $W_{4}$ dengan arah keluar dari simpul $v_{0}$ ke $v_{2}, v_{3}$ dan $v_{4}$.

Selanjutnya akan ditentukan radius, diameter dan center dari graf pada Gambar 7. Menggunakan cara yang sama diperoleh radius, diameter dan center dari semua graf pada tiga arah keluar, yang ditunjukkan pada Tabel 3 berikut :

Tabel 3 Hasil radius, diameter dan titik sentral graf fuzzy roda berarah $W_{4}$ dengan tiga arah keluar

\begin{tabular}{|c|c|c|c|}
\hline Tiga arah keluar & Radius & Diameter & Titik sentral \\
\hline$v_{0} \operatorname{ke} v_{1}, v_{2}$ dan $v_{3}$ & 0.05 & 0.12 & $v_{0}$ \\
\hline$v_{0} \operatorname{ke} v_{1}, v_{2}$ dan $v_{4}$ & 0.04 & 0.09 & $v_{3}$ \\
\hline$v_{0} \operatorname{ke} v_{1}, v_{3}$ dan $v_{4}$ & 0.06 & 0.12 & $v_{0}$ \\
\hline$v_{0} \operatorname{ke} v_{2}, v_{3}$ dan $v_{4}$ & 0.06 & 0.16 & $v_{0}$ dan $v_{1}$ \\
\hline
\end{tabular}

Berdasarkan Tabel 3 pada arah $v_{0}$ ke $v_{1}, v_{2}$ dan $v_{3}, \quad v_{0}$ ke $v_{1}, v_{2}$ dan $v_{4}, \quad v_{0}$ ke $v_{1}, v_{3}$ dan $v_{4}$ memliki center berupa graf trivial. Sedangkan pada $v_{0}$ ke $v_{2}, v_{3}$ dan $v_{4}$ diperoleh center berupa graf terhubung, yang diilustrasikan pada Gambar 8 berikut. 


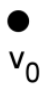

(a) Center dari $v_{0}$ ke $v_{1}, v_{2}$ dan $v_{3}$

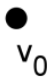

(c) Center dari $v_{0} k e v_{1}, v_{3}$ dan $v_{4}$ (b) Center dari $v_{0}$ ke $v_{1}, v_{2}$ dan $v_{4}$

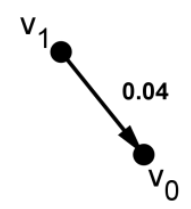

(d) Center dari $v_{0} k e v_{2}, v_{3}$ dan $v_{4}$

Gambar 8 Empat center graf fuzzy roda berarah $W_{4}$ dari tiga arah keluar

\section{PENUTUP}

Penentuan radius, diameter dan center pada graf fuzzy diawali dengan menentukan jarak fuzzy. Kemudian, dicari eksentrisitas fuzzy dari setiap simpul di $G$ dengan nilai maksimum dari jarak fuzzy. Setelah eksentrisitas fuzzy diperoleh, ditentukan radius fuzzy yaitu berupa nilai minimum dari eksentrisitas fuzzy, diameter fuzzy yaitu nilai minimum dari eksentrisitas fuzzy dan titik sentral yaitu titik yang memiliki nilai eksentrisitas yang minimum. Berdasarkan penelitian yang dilakukan disimpulkan bahwa radius dan diameter pada 1 arah keluar, 2 arah keluar dan 3 arah keluar berupa nilai dengan interval tertutup $[0,1]$. Center berupa subgraf yang berbeda-beda yaitu graf trivial, graf kosong dan graf terhubung. Arah pada graf fuzzy roda berarah $W_{4}$ mempengaruhi radius, diameter dan center.

\section{DAFTAR PUSTAKA}

[1] Munir R. Matematika Diskrit. Ed ke 3. Bandung: Informatika; 2010

[2] Wijaya A. Matematika Diskrit. Bandung: Politeknik Telkom; 2009.

[3] Chartrand G, Lesniak L. Graphs and Digraphs. United States of America: RC Press; 1996.

[4] Chandrasekaran E dan Sathyaseelan N. Fuzzy Node Fuzzy Graph and Its Cluster Analysis. International Journal of Engineering Research and Applications.2012; 2:733-738.

[5] Kiss A. An Application of Fuzzy Graphs in Database Theory. Pure Mathematics and Applicationts. 1991; 1:337-342.

[6] Mathew S, Moderson JN, dan Malik DS. Fuzzy Graph Theory. United States of America: Springer International Publishing; 2018.

[7] Moderson JN dan Nair Premchand S. Fuzzy Graphs and Fuzzy Hypergraphs. New York: Physica Verlag Heidelberg; 2000.

[8] Mathew JK. A Characterization of Fuzzy Self Centered Graphs, Annals of Fuzzy Mathematics and Informatics. 2015; 10:249-260.

AYU FITRIANI : : Jurusan Matematika FMIPA UNTAN, Pontianak ayufitriani510@gmail.com

MARIATUL KIFTIAH : Jurusan Matematika FMIPA UNTAN, Pontianak kiftiahmariatul@math.untan.ac.id

FRANSISKUS FRAN : Jurusan Matematika FMIPA UNTAN, Pontianak frandly88@gmail.com 